\title{
ISOLATION OF TYPHOID BACILLI FROM URINE*
}

\author{
KA N-ICHIRo MORIShima and OScar TEAgUe \\ From the Quarantine Laboratory, Health Officer's Department, Port of New York
}

The detection of chronic typhoid carriers has come to be recognized as a factor of prime importance in any campaign to reduce the typhoid rate in a community. The agglutination test may cast a stuspicion on certain persons, but the ultimate discovery of the carrier must rest on the isolation of typhoid bacilli from the feces and urine. The isolation of typhoid bacilli from stools has been extensively studied and many special methods have been devised; the urine, however, has received but scant attention, probably because the typhoid bacilli, when present at all, are usually in enormous numbers and can then be readily isolated by inoculating a drop of the urine on Conradi-Drigalski or Endo plates. It would seem desirable, however, to be able to recover typhoid bacilli also from the smaller percentage of urines that do not contain them in large numbers. This is especially true, since the urine sometimes contains typhoid bacilli when the feces are negative.

Hospitals are beginning to require several negative reports on the feces of typhoid patients before they are discharged; obviously, it is equally important that the urine should be shown to be free from typhoid bacilli. This, then, also shows the need of a simple, practical, and yet delicate method of recovering typhoid bacilli from urine. We have attempted to devise such a method.

Urine for routine examination will not be collected and delivered to the laboratory free from extraneous bacterial contaminations. For enrichment it is necessary, therefore, to provide a medium that will allow the typhoid bacilli to multiply, while inhibiting to a certain extent the growth of other bacteria. In many instances the urine itself was found to serve this purpose, but occasional specimens of urine inhibited the growth of the typhoid bacilli; it then was necessary to dilute the urine in order to be sure that it wotld always allow the multiplication of the typhoid bacilli. Parallel experiments were performed to determine whether the addition of dextrose or broth would yield better results than simply diluting with distilled water or saline solution.

* Received for publication February 8, 1917. 
Our first experiments were carried out with nutrient broth of reaction +1 , and it was found that 1 part of the broth to approximately 2 parts of the typhoid urine gave the best results; if more broth was added, the other bacteria were likely to overgrow the typhoid bacilli.

The diluted urine is by no means a perfect enrichment medium for the typhoid bacillus; other bacteria multiply in it also. We therefore inoculate, after 24 hours' incubation, upon solid medium that is selective for typhoid bacilli. For this purpose, we employ the eosin brilliantgreen agar of Teague and Clurman.

This medium is prepared as follows: 1 pound of chopped becf is soaked in 1000 c.c. of distilled water in the ice-box over night. The fluid is squeezed through cheese cloth, heated and passed through filter paper. To the filtrate are added agar $(1.5 \%)$, Witte's peptone $(1 \%)$, and chemically purc sodium chlorid $(0.25 \%)$. This mixture is heated in the autoclave at 15 bs. pressure for 20 minutes. The reaction is brought to +1 (hot titration) and the medium is cleared with egg white and filtered through cotton. It is then placed in flasks in amounts of 200 c.c., sterilized in the autoclave, and stored for use. To $50 \mathrm{c.c}$. of the agar are added $1 / 2 \mathrm{gm}$. lactose, $1 \mathrm{c.c}$ of $3 \%$ eosin solution, and 1 c.c. of $0.2 \%$ brilliant-green solution. The agar is shaken and poured into Petri dishes.

Whatever selective medium is being used for typhoid stools in a given laboratory should be employed for the urine also, since the full effectiveness of these media is obtained only after considerable experience with them. Only those media that inhibit the growth of most strains of $B$. coli should be used; the Conradi-Drigalski and Endo media are not satisfactory for the urine after incubation.

The manner of inoculating the plates after incubation of the urinebroth mixture is very important. Often there is an enormous multiplication of both typhoid bacilli and another bacillus that grows on the eosin brilliant-green plate; hence, unless the material is greatly diluted, the typhoid colonies are apt to be buried under a confluent growth of the latter organism.

As a routine procedure, we prepare from the incubated mixture dilutions as follows: $1: 10,1: 100,1: 1000,1: 10,000,1: 100,000$ and $1: 1,000,000$. Our saline solution is sterilized in 9 c.c. amounts, so these dilutions are quickly made. We then inoculate 1 loop of the $1: 1,000,000,1: 10,000$ and $1: 100$ dilution, and 1 loop of the original, each on a quadrant of the eosin brilliant-green plate. In this way, isolated colonies are always obtained on at least one of the quadrants.

Instead of preparing the dilutions described above, the inoculation of the incubated urine-broth mixture may be performed in the way 
that is practiced in Japan for feces. The bottom of the eosin brilliantgreen plate is ruled off with a wax pencil in the manner indicated in Figure 1. A loopful of the inctbated urine-broth mixture is spread uniformly over the areas $\mathrm{A}$ and $\mathrm{B}$. Without heating the loop, material is streaked from the base line of $A$ over the surface of $C$, and from the base line of $\mathrm{B}$ over the area $\mathrm{D}$. Then the loop is streaked over the area $E$, just touching the material in $C$ at each stroke, and over $F$, first touching the material in $\mathrm{D}$; in like manner from $\mathrm{E}$ over $\mathrm{G}$, and from $\mathrm{F}$ over $\mathrm{H}$. In this way an extreme dilution of the material is secured for the lower half of the plate.

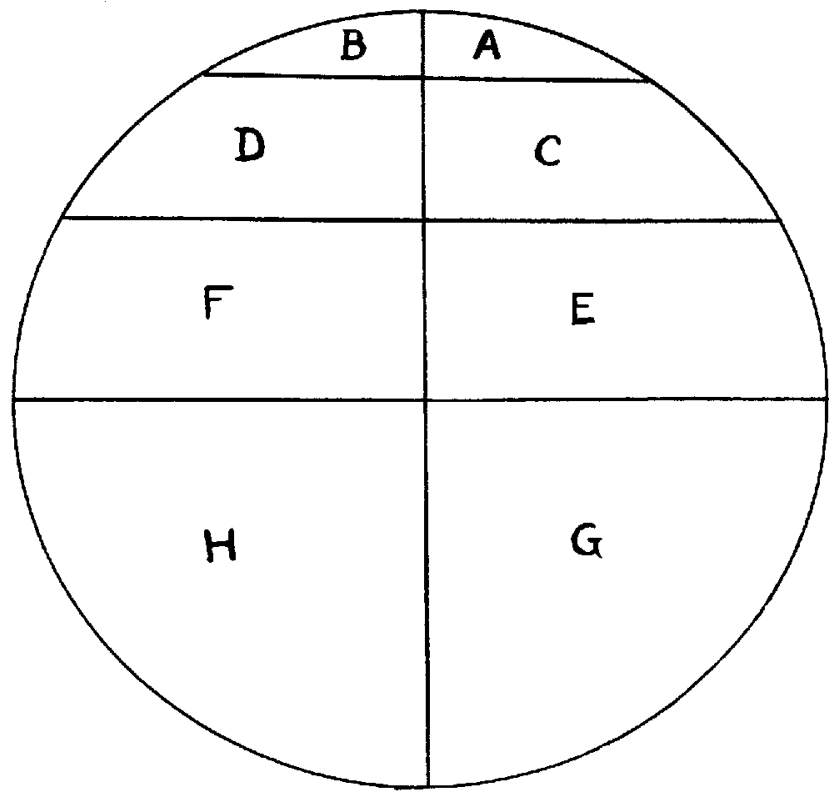

Fig. 1.-Bottom of eosin brillant-green plate, rulcd off for inoculation for incubated urine-broth mixture.

The first series of tests comprised 101 specimens of urine from typhoid patients, convalescents, and suspected typhoids at the Hoffman Island hospital. The urine was collected usually between $6 \mathrm{a} . \mathrm{m}$. and 8 a. m., and was delivered at the laboratory at about 11:30 a. m. No attempt was made to sterilize the meatus of the urethra, nor was the first portion of urine that was passed discarded in order to reduce the amount of extraneous bacterial contamination. None of the specimens was obtained by catheterization. 
Upon arrival at the laboratory, the urine was shaken and two large loopfuls were inoculated upon the surface of an eosin brilliant-green plate. About half as much broth as there was urine in the bottle was then added, and the mixture was incubated over night. The urine was not measured, the broth being added until it seemed about the right amount, as judged roughly by the eye. The amount of urine used for the test was usually about 2 or 3 ounces. After 18 to 24 hours' incubation, dilutions were made and an eosin brilliant-green plate was inoculated in the manner already described. If the plate inoctulated directly with the urine showed typhoid colonies on the following day, it would, of course, be unnecessary, as a routine procedure, to make

TABLE 1

Results of Tests on Urine and Urine-Brotil Inoculated on Eosin Brilliant-Green Plate for Isolation of Typjoid Bacilli

\begin{tabular}{c|c}
\hline Urine Plated Directly & $\begin{array}{c}\text { Urine Broth Incubated } \\
\text { for } 18 \text { to 24 Hours } \\
\text { and then Plated }\end{array}$ \\
\hline+++ & +++ \\
++++ & +++ \\
+++ & +++ \\
+++ & +++ \\
+++ & +++ \\
++++ & +++ \\
+++ & ++ \\
+++ & ++ \\
++ & +++ \\
\hline
\end{tabular}

$++t=$ numetous typhoid colonics.

$++=$ fairly numerous typhoid colonies.

E $=$ few typhoid colonies.

inoculations from the incubated urine-broth mixture; but in order to compare the results of the two methods, this was done in every instance in these tests. In Table 1, the samples of urine that were negative by both tests are omitted.

It is seen from Table 1 that 3 of the 19 positive urines were negative after direct plating, and positive after incubation with broth; in only 1 instance was the typhoid bacillus overgrown by other bacteria during the incubation of the urine with broth. 
The second series of tests included 173 specimens of urine from 10 patients known to have typhoid fever. The specimens were collected without any atempt at the prevention of contaminations, at various stages of the disease and during convalescence, up to the time of discharge. Two loopfuls of the urine were inoculated directly upon an eosin brilliant-green plate. Ten c.c. amounts of the urine were pipetted into several test tubes; one tube was incubated without further addition and to each of the others were added 5 c.c. of broth, $3 \%$ dextrose in distilled water, or 5 c.c. of $0.6 \%$ sodium-chlorid solution, distilled water. After incubation, dilutions of the contents of the different tubes were prepared in the same manner for each, and eosin brilliant-green plates were inoculated as described in connection with Table 1 . The results of these comparative tests are recorded in Table 2 .

The results of the 161 tests shown in Table 2, in which the urines were incubated with broth, demonstrate 25 specimens positive on direct plating; 56 positive after incubation with broth; 2 positive on direct plating and negative after incubation with broth; 33 positive after incubation with broth and negative on direct plating, and 23 positive by both tests. Thus it is seen that out of a total of 58 positive urines, 33 , or considerably more than lialf, would have been missed if the urines had been inoculated directly upon plates. For the sake of convenience and uniformity, only 10 c.c. amounts of urine were used in these tests; it seems probable that if larger amounts had been employed, still more positive results would have been obtained.

Broth was not added to 12 of the urines, but they were tested after enrichment, in the manner indicated in Table 2. The examination of all urines by the different methods yielded 74 positives out of 173 specimens. The comparative results from direct plating and from. plating after enrichment showed 72 specimens positive after enrichment; 30 positive on direct plating; 28 positive by both methods ; 2 positive on direct plating and negative after enrichment, and 44 positive after enrichment and negative on direct plating. Hence, of the 74 positive urines, 44 would have been overlooked if the urines had been inoculated directly on plates without enrichment.

Table 2 indicates that better results are obtained by incubating the urine plus broth than by incubating the urine alone; of 148 such comparative tests, 14 specimens of urine incubated with broth, positive, and alone, negative; 5 specimens incubated with broth, negative and alone, positive; 37 specimens of urine incubated positive by both tests, and 92 specimens incubated negative by both tests. 
TABLE 2

Results of Tests on Urine Inoculated on Eosin Briletant-Green Plate for Isolation of Typhoid Bacilli

\begin{tabular}{|c|c|c|c|c|c|c|}
\hline \multirow[b]{2}{*}{ Patient } & \multirow[b]{2}{*}{ Directly } & \multicolumn{5}{|c|}{ After Incubation with } \\
\hline & & Broth & $\begin{array}{l}\text { Dextrose } \\
\text { Solution }\end{array}$ & $\begin{array}{l}\text { Urine } \\
\text { Alone }\end{array}$ & $\begin{array}{l}\text { Sodium } \\
\text { Chlorid } \\
\text { Solution }\end{array}$ & $\begin{array}{l}\text { Distilled } \\
\text { Water }\end{array}$ \\
\hline B. ...... & $\begin{array}{c}++ \\
++ \\
++ \\
= \\
\pm \\
= \\
= \\
= \\
=\end{array}$ & 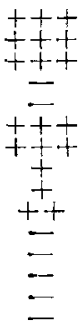 & $\begin{array}{c}\because++ \\
+++ \\
++ \\
\because++ \\
++ \\
\pm \\
= \\
= \\
=\end{array}$ & 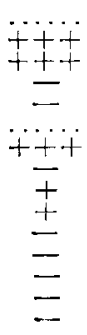 & & \\
\hline And. ... & $\begin{array}{l}= \\
= \\
= \\
=\end{array}$ & $\begin{array}{c}+++ \\
= \\
= \\
=\end{array}$ & $\begin{array}{l}\cdots \\
= \\
= \\
= \\
=\end{array}$ & $\begin{array}{l}\cdots \\
= \\
= \\
=\end{array}$ & & \\
\hline Per. ..... & $\begin{array}{l}E \\
E \\
= \\
= \\
= \\
=\end{array}$ & $\begin{array}{l}- \\
\pm \\
\pm \\
+ \\
++ \\
\pm \\
-\end{array}$ & $\begin{array}{l}\bar{E} \\
\bar{E} \\
\overline{+} \\
\cdots \\
\bar{E} \\
\bar{E}\end{array}$ & $\begin{array}{l}= \\
= \\
= \\
\bar{E} \\
= \\
=\end{array}$ & v & \\
\hline San. .... & $\begin{array}{l}E \\
E \\
E \\
E\end{array}$ & $\begin{array}{c}++1 \\
= \\
= \\
=\end{array}$ & $\begin{array}{c}\cdots \\
\cdots \\
\cdots \\
\cdots \\
\cdots \cdots \\
\cdots\end{array}$ & $\begin{array}{c}\cdots \\
\cdots \\
\cdots \\
\cdots \\
\cdots \cdots\end{array}$ & & \\
\hline Vit. & $\begin{array}{l}= \\
= \\
= \\
=\end{array}$ & $\begin{array}{c}+++ \\
++1 \\
- \\
\square \\
\pm\end{array}$ & $\begin{array}{c}\cdots \\
\cdots \cdots \\
\cdots \\
= \\
= \\
\end{array}$ & $\begin{array}{c}+\not \\
\cdots \\
\cdots \\
= \\
= \\
=\end{array}$ & & \\
\hline P. $\ldots \ldots$ & 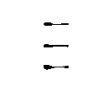 & $\div$ & $\underline{\cdots}$ & $\underline{-}$ & & \\
\hline
\end{tabular}


Isolation of Typhus Bacilli from Urine

TABLE 2 -Continued

Results of Tests on Urine Inoculated on Eosin Brilliayt-Green Plate for Isolation oF TyPhOID Bacilli

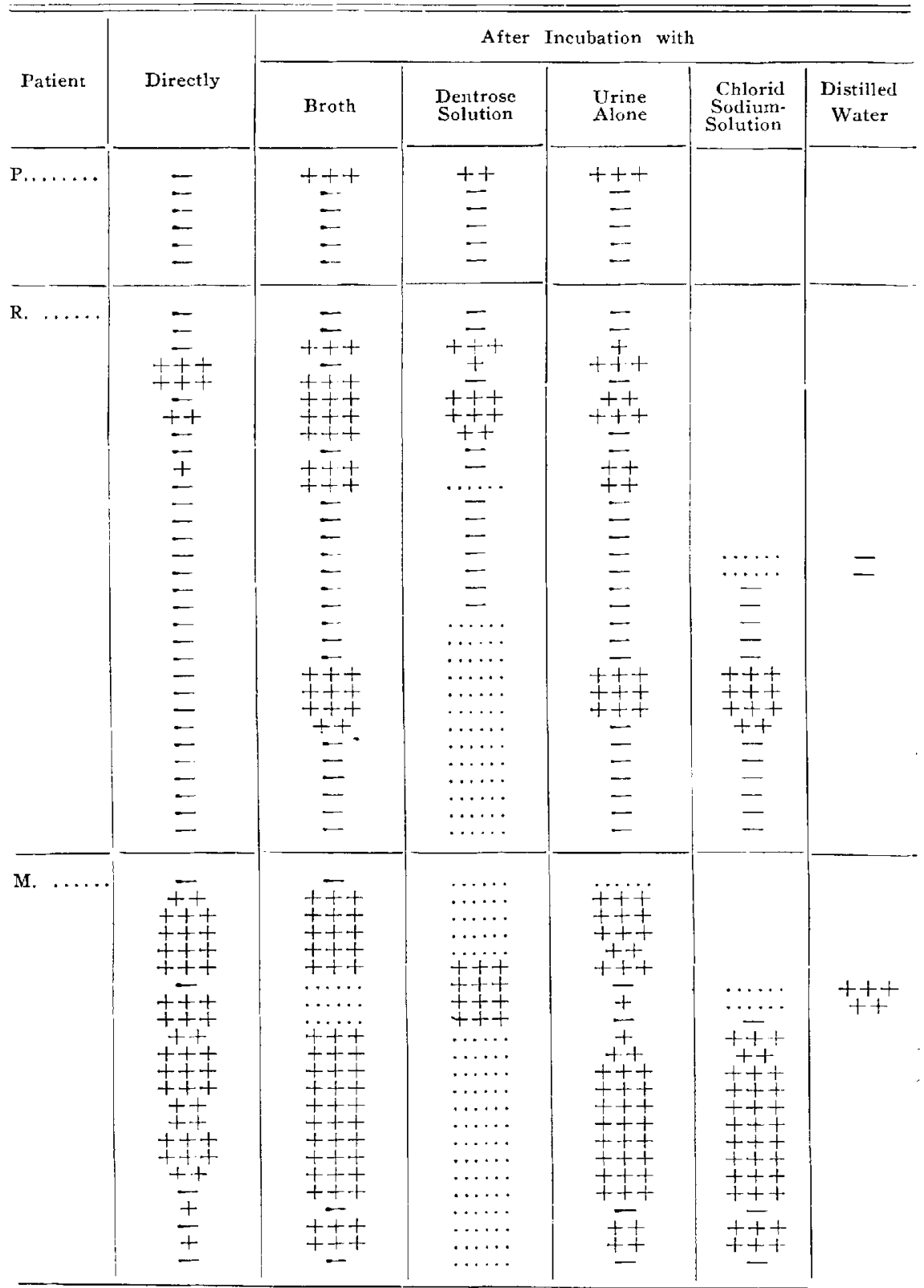


TABLE 2.-Continued

Results of Tests on URine Inoculated on Eosin Brilliant-Green Plate for Isolation of TyFhote Bacilet

\begin{tabular}{|c|c|c|c|c|c|c|}
\hline \multirow[b]{2}{*}{ Patient } & \multirow[b]{2}{*}{ Directly } & \multicolumn{5}{|c|}{ After Incubation with } \\
\hline & & Broth & $\begin{array}{l}\text { Dextrose } \\
\text { Solution }\end{array}$ & $\begin{array}{l}\text { Urine } \\
\text { Alone }\end{array}$ & $\begin{array}{l}\text { Sodium: } \\
\text { Chlorid } \\
\text { Solution }\end{array}$ & $\begin{array}{l}\text { Distilled } \\
\text { Water }\end{array}$ \\
\hline M....... & $\begin{array}{l}E \\
\pm \\
=\end{array}$ & $\begin{array}{l}= \\
= \\
=\end{array}$ & $\begin{array}{l}\ldots \ldots \\
\ldots \ldots \\
\ldots \ldots \\
\ldots \ldots \\
\ldots \ldots\end{array}$ & $\begin{array}{l}E \\
E \\
E\end{array}$ & $\begin{array}{l}\text { 二 } \\
\text { - }\end{array}$ & \\
\hline G. $\ldots \ldots$ & $\begin{array}{l} \pm \\
\pm \\
\pm \\
\pm \\
\pm \\
\pm \\
\pm \\
\pm \\
\vdots \\
\pm \\
\pm \\
\square\end{array}$ & $\begin{array}{c}\cdots \\
\pm \\
+t \\
+ \\
\cdots \\
\cdots \\
\pm \\
++t \\
+ \pm+ \\
\pm \\
\pm \\
\pm \\
\pm \\
\pm \\
\pm \\
\pm \\
\pm\end{array}$ & 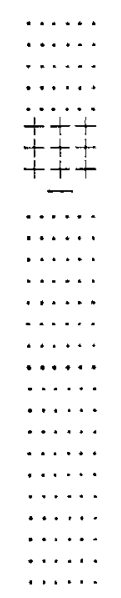 & 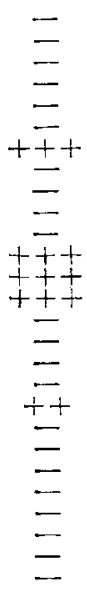 & $\begin{array}{c} \\
= \\
= \\
+++ \\
+ \pm+ \\
\pm \\
= \\
= \\
= \\
= \\
=\end{array}$ & $+\frac{1}{+}$ \\
\hline S. $\ldots$ & $\begin{array}{l}= \\
= \\
+ \pm+1 \\
= \pm+1 \\
+ \pm+ \\
\pm \\
= \\
= \\
= \\
\pm \\
= \\
= \\
=\end{array}$ & 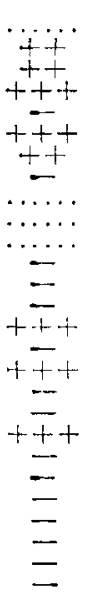 & 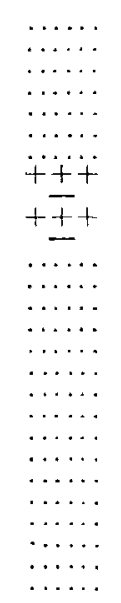 & 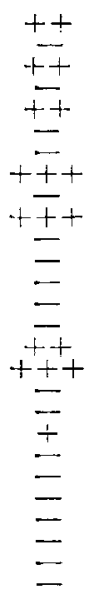 & $\begin{array}{c}\cdots \cdots \\
\bar{z} \\
\bar{z} \\
+\overline{+}+ \\
+ \pm+ \\
\cdots \\
\overline{ \pm} \\
+\overline{+}+ \\
\bar{z} \\
= \\
= \\
=\end{array}$ & $\overline{+}$ \\
\hline
\end{tabular}

$++t=$ numerous typhoid colonies.

$++=$ fairly numerous typhoid colonies.

+ E few typhoid colonies.

- = no typhoid colonies. 
Only 68 comparative tests were made with urine plus broth and urine plus dextrose solution. The results, though not conclusive, indicate that the broth mixture is slightly better. Five specimens of urine were positive with broth and negative with dextrose solution; 3 specimens were negative with broth and positive with dextrose solution; by both tests, 13 were positive, and 41 were negative.

Of 68 comparative tests, made between urines diluted with broth, and urines diluted with sodium-chlorid solution, 1 specimen incubated with broth, negative and with sodium-chlorid solution, positive; no specimen incubated with broth, positive and with sodium-chlorid solution, negative; by both tests, 21 specimens of urine were positive and 46 were negative.

A few comparative tests were carried out with dextrose broth instead of plain nutrient broth and with sterile distilled water in place of the sodium-chlorid solution, but not in sufficient number to furnish evidence as to the value of the methods.

SUMMARY

To isolate typhoid bacilli from urine not collected under aseptic: precautions, streak 2 or 3 large loops of the urine over the surface of an Endo plate or preferably an eosin brilliant-green agar plate; add to the urine approximately one half its volume of nutrient broth and incubate the mixture over night. If the plate inoculated with the urine directly is negative the following morning, prepare dilutions of the incubated mixture of urine and broth and inoculate them on an eosin brilliant-green agar plate. Other special media that inhibit the growth of most strains of $B$. coli, while allowing the development of $B$. typhosus, could probably be substituted for the eosin brilliant-green agar, if one is not familiar with the latter medium. If the typhoid bacilli are present in sufficiently large numbers to yield colonies on the plate inoculated the first day, the incubated urine-broth mixture is, of course, discarded.

Sterilized bottles should be furnished for transporting the urine to the laboratory, and boiled urinals should be used for its collection, when practicable.

The method offers the advantage of subjecting a large amount of the urine to examination, with very little manipulation or loss of time. By its use it is believed that considerably higher percentages of positive results will be obtained in the routine examination of urines for typhoid bacilli than by the methods ustally employed. 